\title{
LATIM, BIQUÍNI E SINFONIA DISCORDANTE: LIINGUAS CLÁSSICAS E METODOLOGIA DE ENSINO ${ }^{1}$ LATIN, BIKINI, AND DISSONANT SYMPHONY: CLASSICAL LANGUAGES AND TEACHING METHODOLOGY
}

\author{
Eduardo Marcant Engelsing ${ }^{2}$
}

Resumo: Neste artigo se discute a visão que os profissionais de Letras têm do latim e do ensino de línguas clássicas. Baseando-se na noção de que o que faz uma língua são capacidades inatas e individuais do ser humano - e não o uso dessa língua entre indivíduos e em comunidade - o estudo de latim se encerra na leitura de textos escritos entre dois e quatros séculos, em oposição a mais de dois milênios de uso do latim, e o ensino de língua é individualista e formalista, em oposição ao social e participativo. Propõe que uma concepção mais ampla de língua e a noção de aprendizagem como crescente participação em atividades letradas podem transformar o estudante, de titubeante leitor de poucos autores, em ativo participante da comunidade que se estende por vários territórios do globo e abarca a produção de vinte séculos de história: a produção mais ampla, mais diversificada, mais influente na história social e literária dos homens.

Palavras-chave: Língua Latina, Ensino de Latim, Metodologia de ensino de Linguas Clássicas, Ensino de Língua Estrangeira.

Abstract: The aim of this paper is to examine how classicists conceive of Latin as a language and the consequences of these ideas for their language teaching. Their conception assumes that a language is based on innate and individual human capabilities and not on language use among people and in communities. Under these assumptions, the study of Latin aims at accessing texts written between two to four centuries rather than the over two-millennia period of Latin use. Furthermore, language teaching is underpinned by an individualistic and formalist approach in opposition to an approach that

1 Uma primeira versão deste artigo, com o título Latim, biquíni e sinfonia discordante: uma resposta a Cláudio Moreno, foi enviada a Zero Hora, como resposta aos textos divulgados pelo professor Cláudio Moreno, em 2007. Atendendo ao contato do editor de Zero Hora, o artigo foi reescrito em diversas versões, de menor tamanho, para a divulgação no jornal. Zero Hora nunca publicou a resposta. Agradeço a Cíntia Vieira Souto e a dois avaliadores anônimos pela leitura deste artigo. Qualquer erro restante é de minha responsabilidade.

2 Professor da Western Washington University, Estados Unidos da América. 
is social and participative. There is, however, a much broader and more productive understanding of Latin and its pedagogy. In this broader conception, language learning aims at increasing the participation of language users in literacy activities and can transform a Latin student from a faltering reader of a few books into an active member of a community that stretches over many regions of the globe and encompasses a twenty-century period of language production. This community's production is the broadest, most diversified, and most influential cultural legacy in the social and literary history of mankind.

Keywords: Latin, Latin teaching, pedagogy of Classical Languages, Foreign Language Teaching.

A Myrna Bier Appel, in memoriam

\section{Introdução}

O ensino de línguas clássicas - latim e grego antigo - vem sofrendo importantes modificações em diversas partes do mundo, sobretudo com o estabelecimento de parâmetros curriculares nacionais, que propõem às línguas antigas o mesmo tipo de ensino sugerido às línguas modernas. Nos parâmetros curriculares elaborados para línguas clássicas nos Estados Unidos, por exemplo, há ênfase para comunicação, contextose comunidades, ${ }^{3}$ e se postula que as habilidades de fala e de escrita - concomitantes à leitura e à compreensão auditiva - sejam desenvolvidas desde o princípio em sala de aula. Enquanto tais diretrizes fixam as bases de um ensino vinculado à reflexão e pesquisa em aprendizagem de línguas adicionais, ${ }^{4}$ na prática de sala de aula, a língua latina (e grega) segue sendo objeto de análise morfossintática e de tradução, e se continua considerando a literatura latina como circunscrita à dúzia de autores e extinta na Antiguidade

3 Para uma discussão dos parâmetros curriculares elaborados nos Estados Unidos, ver Abbott et alii (1998, p. 44-58) e Abbott (1998, p. 36-43). Para uma discussão dos termos comunicação, contextos e comunidades nestes parâmetros, ver Gruber-Miller (2006, p. 9-23). O leitor pode ler os Parâmetros Curriculares para o estudo de línguas clássicas nos Estados Unidos aqui: http:// department.monm.edu/classics/cpl/standards.pdf .

$4 \mathrm{O}$ uso do termo "línguas adicionais" está assentado na bibliografia recente em linguística aplicada. Com ele busca-se evitar as conotações negativas em "segunda língua" e "língua estrangeira", e levar em conta a realidade de que a maioria das pessoas já tem no seu repertório mais de uma língua. Para uma discussão do termo segunda adotado pela área de Aquisição em Segunda Língua, ver Block (2003). Sobre a adoção de "línguas adicionais" em vez de "línguas estrangeiras" ver Schlatter \& Garcez (2012, p. 37).

Organon, Porto Alegre, v. 29, n. 56, p. 99-121, jan/jun. 2014. 
Clássica. O docente de línguas clássicas parece insensível ao que sugerem as áreas que se ocupam com o ensino de línguas e com o uso da linguagem, como se ensinar línguas antigas através do uso exclusivo da língua materna do aluno, e não da própria língua objeto de estudo, fosse uma fatalidade, contingência histórica e linguística irrevocável.

Neste artigo se pretende discutir a visão tradicional que os profissionais de Letras têm do latim e do ensino de línguas clássicas. Baseando-se na noção de que o que faz uma língua são capacidades inatas e individuais do ser humano - e não o uso dessa língua entre os indivíduos e em comunidade - o estudo de latim se encerra na leitura de textos escritos entre dois e quatro séculos, em oposição a mais de dois milênios de uso do latim, e o ensino de língua é individualista e formalista, ${ }^{5} \mathrm{em}$ oposição ao social e participativo. Propõe-se que uma concepção mais ampla de língua e a noção de aprendizagem como crescente participação em atividades letradas e relevantes podem transformar o estudante de latim, de titubeante leitor de poucos autores, em ativo participante da comunidade que se estende por vários territórios do globo e abarca a produção de vinte séculos de história. Saber latim com livre acesso à produção de literatos, historiadores, matemáticos, biólogos, juristas, médicos, arquitetos, filósofos e demais pensadores de todas as disciplinas sem restrição geográfica durante dois milênios é a promessa de ingresso em uma disciplina reexaminada. A discussão a seguir trata de questão ontológica, o que estuda a filologia clássica, e metodológica, como estudá-lo.

5 Individualista porque concebe a compreensão e a aprendizagem de língua como frutos de operações mentais, individuais do aprendiz, e que prescindem de interação social. Formalista porque se crê que a aprendizagem de língua ocorre preponderantemente através do estudo de aspectos linguísticos, estruturais, da língua. Adotamos os termos individualista e formalista porque eles descrevem melhor a concepção de aprendizagem e comunicação que informam diferentes métodos de ensino. Assim, embora o método gramática e tradução e o método direto proponham atividades para a sala de aula diferentes entre si, enquanto um, por exemplo, aconselha o uso da língua alvo e o outro não, ambos nasceram a partir de uma concepção individualista e formalista de aprendizagem. O mesmo acontece, mirabile dictu, com versões do método comunicativo (ver discussão em FIRTH \& WAGNER, 1997). O ponto crucial aqui é por em evidência crenças comuns operativas em diversos métodos de ensino: a explicação de aprendizagem através de capacidades inatas, cerebrais, e o perceber a interação social como dispensável ou secundária para a aprendizagem de línguas. Neste sentido, é importante notar que mesmo os autores e comentadores dos Parâmetros Curriculares nos Estados Unidos (ver nota 3), embora genericamente defendam o uso das quatro habilidades em sala de aula (ler e escrever, falar e ouvir), também adotam o discurso vigente, mentalista, da área de Aquisição em segunda língua. Como consequência disso, mesmo entre estes autores, o uso da língua alvo - o latim - ainda é limitado, e a fala, a escrita e a compreensão auditiva não são vistas como habilidades integradas, mas apenas como subsidiárias para o desenvolvimento da habilidade de leitura. Neste artigo levamos às suas devidas consequências a centralidade dos aspectos interacionais para o uso e a aprendizagem de línguas.

Organon, Porto Alegre, v. 29, n. 56, p. 99-121, jan/jun. 2014. 


\section{O latim morto}

Para explicitar a visão tradicional do profissional de letras clássicas, tomamos como ponto de partida dois textos escritos pelo professor Cláudio Moreno, em 2007, publicados no jornal Zero Hora. Embora nunca desprovidos de opinião, textos mediáticos possuem, em geral, caráter informativo; eles não procuram defender um ponto de vista polêmico (como, por exemplo, um artigo acadêmico), e apresentam fatos como recebidos, inquestionáveis. Essa é a utilidade aqui dos textos de Moreno: eles divulgam a opinião letrada e aceita.

Cláudio Moreno, nos artigos Absurda Sinfonia e Latinório Moderno, ${ }^{6}$ aborda o status do latim, se língua morta ou viva, e avalia a criação, pelo Vaticano, de novas palavras no idioma romano para a denominação de objetos e noções da nossa época. Moreno concede que o latim, após o que se convencionou chamar queda de Roma em 476 A.D., continuou a ser usado por religiosos e intelectuais na Idade Média, embora afirme

é claro que não se tratava de latim em carne e osso, e sim de uma modalidade estilizada a partir da língua usada pelos escritores do Período Clássico, sustentada por regras rígidas que a escola tratou de difundir e consolidar. ...Não havendo mais quem a fale, [uma língua] para de evoluir, seu léxico para de crescer e ela fica cristalizada para sempre... Neste sentido, o Latim realmente morreu. ...Só o Vaticano não o abandonou, ...para suprir o Latim dos milhares de vocábulos que ele deixou de incorporar neste milênio e meio em que ficou paralisado, criaram-se comissões que tentam propor designações "alatinadas" para os fatos e os objetos corriqueiros do mundo moderno, ...uma armadilha em que caíram (e vão continuar caindo) os puristas de todas as épocas: em vez de absorver vocábulos modernos usados em todo o planeta (como táxi, hotel, sauna, jeans, etc.) propõem [neolatinismos, palavras muitas vezes] distantes da brevidade e da concisão que sempre caracterizaram a língua dos romanos, [e que] exprimem as crenças e os preconceitos do seu autor, [como, por exemplo,] vesticula balnearis bikiniana, para "biquíni", e absurda sinfonia, para “jazz”. (MORENO, 2007)

Ao final do segundo artigo, Moreno oferece um consolo aos estudantes do latim "morto", com um poder de síntese extraordinário da proposta e método atuais (desde o século XVI) empregados por toda a área de línguas

6 Ambos os artigos foram publicados, respectivamente, em 3 e 17 de fevereiro de 2007, no jornal Zero Hora, em Porto Alegre. 
clássicas: "examinar o Lexicon Recentis Latinitatis" (ou qualquer léxico de língua latina, acrescento, sem mudança de significado), "no entanto, serve para aumentar a consciência sobre nosso próprio idioma".

Moreno não está só; o seu discurso é representativo do que pensa a grande maioria de leigos e profissionais da área e expressa a perspectiva ainda vigente no ensino de línguas clássicas: o latim é uma língua morta desde 476 A.D.; uma língua é sustentada por regras rígidas (gramaticais); o ensino do latim consiste em examinar dicionários, cuja função é aumentar a consciência do sentido original do léxico português (ou inglês, ou alemão, conforme a língua nativa do aprendiz). Embora tais artigos pareçam inofensivos e até divertidos, a perspectiva que subjaz ali segue condicionando o conteúdo e a metodologia de ensino em escolas e universidades, e suas consequências são, como veremos, enquanto humana e socialmente excludentes, pedagogicamente desastrosas.

\section{3. $O$ uso crescente do latim}

Visível em países da Europa e nos Estados Unidos, desde os anos 80, o número de usuários de latim cresce continuamente no mundo. Isso sim, o interessado em participar do orbis Latinus deve fazê-lo em latim, que é a senha de ingresso na comunidade de usuários. Mas não é preciso ir ao google Latinum, que há, para nos convencermos da vitalidade do latim hoje. Basta buscar na internet Ephemeris, jornal diário para o leitor na língua, ou Nuntii Latini Radiophoniae Finnicae Generalis, que, como o nome diz, emite notícias por rádio desde a Finlândia, ou ainda visitar os incontáveis grupos de discussão, escrita ou oral, no facebook.

Se, como diz o professor no primeiro artigo, "em rigorosos termos científicos, uma língua morre quando desaparecem aqueles que a usavam", estaremos atentos aos seus próximos escritos, quando descobrir fatos eloquentes. Durante biênio, todas as atividades acadêmicas (aulas, trabalhos, teses) e extracurriculares (almoços, jantas, confraternizações) do Mestrado na Universidade do Kentucky, nos Estados Unidos, onde fui aluno, realizam-se em nenhuma outra língua senão em latim. De fato, atualmente, pode-se completar o currículo escolar, do primário à pós-graduação, visitando cursos ministrados no idioma de César. ${ }^{7}$ Em julho de 2006, durante quatro dias, acadêmicos provenientes de 22 países

7 Para mencionar alguns exemplos: para o primário, na Schola Nova (Bélgica); para o secundário, Vivarium Novum (Itália); para a graduação, Western Washington University (EUA), Wyoming Catholic College (EUA), University of Massachusetts, Boston (EUA); para a pós-graduação, University of Kentucky (EUA).

Organon, Porto Alegre, v. 29, n. 56, p. 99-121, jan/jun. 2014 
reuniram-se, na Espanha, para discutir propostas de ensino; durante todo o congresso utilizou-se exclusivamente a língua romana. Um dos frutos concretos do encontro na Espanha foi o surgimento de novas associações de latim, reunindo professores, jovens estudantes, amantes da língua. Uma delas, PHILIA, cujos participantes majoritariamente provêm da Europa Oriental, organizou em junho do ano seguinte, em Nápoles, Itália, um dos maiores encontros da história de Latim Vivo - movimento surgido nos anos 60 para revitalizar os estudos desta língua - contando com a presença de grande número dos mais respeitados latinistas do planeta, como Michael von Albrecht (Universidade de Heidelberg, Alemanha), Dirk Sacré (Universidade Católica de Leuven, Bélgica), Kurt Smolak (Universidade de Viena, Áustria), Oleg Nikitinski (pesquisador do Thesaurus Linguae Latinae, Munique, Alemanha), Terence Tunberg (Universidade do Kentucky, Estados Unidos), membros da Academia Latinitati Fovendae (ALF), uma associação de professores universitários fundada em 1967, com o propósito explícito de fomentar o uso do latim. Entre os fundadores da ALF, em 1967, estava o brasileiro Vandick Londres da Nóbrega. Recentemente, ALF promoveu encontro internacional em Regensburg (Alemanha), em 2009, e em Viena (Áustria), em 2013. Encontros regionais e anuais acontecem em diversas partes da Polônia, Itália, Alemanha, Espanha, França e Estados Unidos. ${ }^{8}$ No Brasil, o primeiro encontro internacional de latim ativo ocorreu entre Porto Alegre e São Leopoldo, em 2001, e contou com uma centena de participantes (MORGAN, 2001).

Não se trata aqui de exemplos isolados, mas representativos, de movimento crescente a partir da conscientização de que aprendemos línguas integrando-nos em comunidades de uso.

\section{Como os seres humanos aprendem línguas}

São várias as razões pelas quais se volta a enfatizar a escritura e a fala na língua antiga, mas de todas, creio, nos importam as que dizem respeito às questões de ensino. É preciso, antes de tudo, perguntarmo-nos não como se tem ensinado latim (e grego), mas como se concebe, atualmente, a aprendizagem de língua entre os seres humanos. Uma das mais radicais redefinições da área de Aquisição em Segunda Língua, a partir de crítica etnometodológica - disciplina que estuda os métodos criados pelas pessoas para fazerem tarefas comuns do dia-a-dia -, é a substituição de um modelo

8 O leitor pode encontrar uma lista parcial de eventos anuais para os usuários do latim na página web da Academia Latinitati Fovendae. 
cognitivista, cerebral, que tenta explicar o processo de aquisição de língua através de hipóteses do que acontece na mente humana, evidentemente inacessível ao pesquisador, para um modelo descritivo, sociointeracional, em que se analisam os recursos de que lançam mão os usuários de língua para comunicar-se (gestos, pausas, entonações de voz, linguagem verbal, etc.). Essa redefinição da aprendizagem de línguas é produtiva em duplo sentido: não apenas documenta os sinais observáveis e, portanto, acessíveis ao analista, utilizados naturalmente por qualquer ser humano em interação social, mas chama a atenção para o fato de que, justamente porque utilizamos tais recursos também observáveis aos nossos interlocutores, a comunicação acontece. Através destes recursos interacionais, continuamente monitorados e reorganizados pelos interlocutores entre os turnos da fala, torna-se possível a realização conjunta de tarefas diárias mesmo entre pessoas recém conhecidas ou mesmo entre falantes que mal conhecem os aspectos formais da língua um do outro (FIRTH, 1996, 2009). Ora, perceber que os seres humanos comunicam-se utilizando um método irremediavelmente interacional é perceber que uso e aprendizagem de língua são inseparáveis (MARKEE, 1994; FIRTH \& WAGNER, 2007; SCHLATTER et alii, 2004). Do ponto de vista do ensino, não estamos aqui querendo reivindicar que o latim vive - discussão inócua -, mas questionar a visão preponderante em nossa sociedade sobre linguagem e comunicação que permite trabalhar-se com o latim "morto", um modelo de língua e aprendizagem baseado na crença de que o sentido das palavras está inserido nestes pontos negros contra o fundo branco que você vê nesta página, e de que habilidades inatas, mentais e individuais, são capazes de dar-lhes significado. Para o estudante de línguas clássicas, o sentido da linguagem está no papel e independe da interação humana. Através do manejo de dicionários e de livros de gramática, ler em línguas clássicas é resgatar o sentido que sempre esteve ali, depositado entre estes pontos negros, há mais de dois mil anos.

Nós, seres humanos, inexoravelmente imersos em linguagem (em várias linguagens, em vários idiomas) talvez não entendamos de imediato o quão problemático seja o modelo de linguagem descrito no final do parágrafo anterior, o que se entende por leitura em línguas clássicas. Imersos no paradigma tradicional, não entendemos que nesta prática irredutível da sala de aula de filologia clássica de abordar um texto com gramática e dicionários, traduzindo palavra a palavra e reorganizando o texto através de análise morfossintática, não nos conduz a um milímetro mais próximo de aprendermos e entendermos latim ou grego. No intento de nos desacoplarmos do paradigma operante na área, talvez seja útil recorrer a duas metáforas. A primeira metáfora, a da Sala Chinesa, parece

Organon, Porto Alegre, v. 29, n. 56, p. 99-121, jan/jun. 2014. 
descrever a prática diária de classicistas e estudantes de línguas clássicas, e captar com precisão o alcance pedagógico do ensino atual. A metáfora da Sala Chinesa foi criada por John Searle (1980) para demonstrar que uma máquina, um computador, jamais será capaz de entender a linguagem humana. Não importa aqui uma discussão mais aprofundada do seu uso em Searle, mas como tal metáfora põe de manifesto o modelo de leitura e de proficiência em língua vigente em filologia clássica.

5. O modelo de linguagem, de leitura e de proficiência de línguas em filologia clássica

Eis o funcionamento da Sala Chinesa: no seu interior há alguém que opera a sala; perguntas, escritas em chinês, são inseridas dentro da sala através de uma portinhola. $\mathrm{O}$ operador, no interior da sala, com o auxilio de códigos escritos em sua língua materna (no nosso caso, português) que explicitam a resposta mais adequada para cada pergunta, responde a mensagem recebida e devolve a resposta pela portinhola. Sem dúvida, é preciso um bom arsenal de códigos e manuais (dicionários e gramáticas), que possam conter todas as respostas para todas as perguntas. Além disso, tal operação pode durar muito tempo, dependendo do grau de organização no interior da sala (por exemplo, certas perguntas iniciando com tais letras ou palavras estariam em certos códigos e não em outros) e do grau de experiência, em manejar os instrumentos da sala, do operador. A importância da Sala Chinesa é essa: do ponto de vista exterior da sala, do indivíduo que recebe a resposta do operador, a impressão é de que o operador da Sala sabe chinês. Quem enviou uma pergunta em chinês e recebeu uma resposta em chinês adequada àquela pergunta juraria que quem respondeu é proficiente na língua. No entanto, e este no entanto é de importância absoluta, o operador da sala manejou apenas e tão somente manuais na sua própria língua, português. Manejando manuais em português, o operador leu "para X a resposta é Y". Foi através do português que o operador foi capaz de enviar a resposta em chinês. Como dizem Button et alii (1995, p.11-37), o operador sequer necessita saber que se trata da língua chinesa. De fato, poderiam ser apenas símbolos matemáticos, e não uma língua com morfologia e sintaxe, e a sua habilidade em manejar os códigos e demais instrumentos da sala dariam o mesmo resultado. $\mathrm{Ou}$ seja, a aparência para a pessoa no exterior seria a mesma: se pressuporia que o operador sabe matemática. Mas tudo o que o operador sabe é português, porque ele apenas e exclusivamente maneja códigos, manuais, 
em português. Se o operador, para o bom manejo da sala, sequer necessita saber se aquilo que envia é uma língua humana ou símbolos matemáticos, utilizando sempre manuais e códigos em sua própria língua, ele tampouco necessita conhecer nada da morfologia ou sintaxe do que envia, nada sobre as partes que o compõem ou o possível (no caso de ser uma língua) som a que os símbolos possam corresponder.

Como Button et alii (1995) indicam, é claro que o funcionamento da Sala Chinesa evidencia conhecimento de chinês. Mas tal conhecimento é de quem escreveu os códigos e os manuais. No entanto, os códigos e manuais da Sala Chinesa foram escritos de tal forma que os seus operadores pudessem absolutamente prescindir de todo e qualquer conhecimento de língua chinesa, e dependessem inteiramente do conhecimento de língua portuguesa.

Igualmente, para os usos específicos da metáfora em Searle, um computador, ao mostrar na tela injunções de frases ou emitir sons humanos, parece demonstrar conhecimento de língua. Contudo, o conhecimento de língua pertence a quem criou os programas específicos nos quais tal língua é usada, programas que a tecnologia atual é capaz de transformar em códigos que o hardware processa e decodifica. Crer que o computador, composto de silicone e metais, e que funciona a base de operações elétricas de íons e prótons, tenha conhecimento de língua(s) ou qualquer habilidade cognitiva é como pressupor que a placa de lata, fixa em prédio público, nos esteja dirigindo uma admoestação imperativa - Não fume! - preocupada com o meio-ambiente, com a saúde própria e alheia (BUTTON, p.18).

Assim, quando recorremos ao Tradutor do Google e escrevemos "usus/ quem penes arbitrium est et ius et norma loquendi" e recebemos em português, "o uso, em poder de quem é o julgamento tanto da jurisdição quanto da norma da fala", não supomos que o google saiba latim ou português, e muito menos que seja grande apreciador de Horácio. Fazer "usus" corresponder a "o uso", e assim por diante até chegar a que "usus/ quem penes arbitrium..." correspondesse à frase em português foi operação inteiramente mecânica. Como o computador, matéria sintética e fios, dá a impressão de saber línguas e de traduzir a frase em latim quando sequer é capaz de cognição e inteligência, o operador da Sala Chinesa montou mecanicamente a frase em chinês através do seu conhecimento (não mecânico) do português. O operador da Sala Chinesa dá a impressão de saber chinês, mas sabe tão somente português.

Com a segunda metáfora intento sacar de vez o leitor da Sala Chinesa. Ludwig Wittgenstein articula em Investigações Filosóficas (1953) a ideia de que a atribuição de sentido à língua só é possível aos usuários desta língua dentro do jogo da linguagem. Em diversos momentos, Wittgenstein

Organon, Porto Alegre, v. 29, n. 56, p. 99-121, jan/jun. 2014. 
evoca a imagem de jogadores de xadrez e procura refletir sobre a relação entre o jogar xadrez e as regras do jogo. Os jogadores, ao jogarem, não pensam objetivamente nas regras do xadrez, mas em mover as suas peças, protegendo-as o quanto possível, para derrubar o rei do adversário. Em circunstâncias normais, a nenhum jogador ocorreria mover um peão em círculos ou atirá-lo contra o nariz do jogador oponente. Para os jogadores de xadrez mover um peão em círculos ou atirá-lo contra o nariz do adversário não significa nada. $\mathrm{O}$ movimento em círculos do peão ou a agressão física contra o adversário não tem lugar no jogo, não consta nas possibilidades do xadrez. No entanto, é importante notar que Wittgenstein usa a metáfora do "sentido-da-língua-tão-somente-dentro-do-jogo-da-linguagem" para demonstrar a impossibilidade de se buscar sentido na linguagem em abstrato, teoricamente, anterior ao próprio jogo: o sentido do jogo não são as suas regras, mas se faz ao se estar jogando, no embate temporal e local - portanto finito e imprevisível - entre os jogadores. Suponha que o seu oponente, seguindo as regras do jogo, começasse a mover as peças aleatoriamente. Você diria: "Vamos, você não quer jogar?" Assim, ser jogador dentro do jogo da linguagem como condição para atribuir sentido à língua tem tal importância: jogar xadrez não é seguir as regras do jogo - as regras são implícitas, tácitas, subentendidas. Jogar xadrez é articular-se estrategicamente, respondendo a cada lance do adversário, para atingirmos um fim específico. É curioso atentar para a escolha de Wittgenstein: ele usou o exemplo do jogo de xadrez, o paroxismo da atividade lúdica cerebral, cujo êxito depende do raciocínio e onde as trocas verbais não têm a mínima importância, para enfatizar a centralidade do social na interação. ${ }^{9}$

Como aludimos, não cabe aqui tirar todas as consequências de qualquer uma das duas metáforas, da Sala Chinesa (SEARLE, 1980) ou do Jogo da Linguagem (WITTGENSTEIN, 1953), mas apenas utilizá-las para iluminar o que classicistas entendem por ler ou saber latim e grego. Cada uma destas metáforas tem força própria, mas podem aqui serem entendidas como complementares: o manuseador de códigos e manuais em língua portuguesa - como o classicista ou estudante de latim e grego está sempre dentro da Sala Chinesa: ele sabe tão somente português. Estar no jogo da linguagem é estar jogando, usando a língua em interação com outros usuários do lado de fora da Sala Chinesa. ${ }^{10}$

9 Igualmente, Clark (1996) evoca a imagem de dois dançarinos, Fred Astaire e Ginger Rogers, para explorar a idéia de que dançar não é saber as regras da dança; enquanto atividade social, não é sequer a soma da performance de dois indivíduos. Dançar é imprevisível, temporal e local, é a interação sempre única entre as pessoas ao se estar dançando.

10 Para uma articulação mais elaborada destas metáforas aplicadas às práticas da filologia clássica, ver ENGELSING, E. The Chinese Room: on language proficiency and reading in Classics, publicação prevista para 2014. 
Compreender que usar uma língua e aprender uma língua é um e o mesmo fenômeno redesenha vários aspectos do ensino, como, por exemplo, a avaliação. $O$ critério para avaliar um bom aluno não é mais (ou não deveria ser) o seu conhecimento formalista, gramatical, cuja única finalidade é satisfazer a exigência da própria escola, mas a sua capacidade de realizar ações no mundo, como ler e escrever cartas, contar e discutir uma estória, participar ativamente nas comunidades em que se move, expressando-se eficiente e adequadamente nos contextos em que desenvolve a sua ação (inter alia, SCHLATTER et alii, 2004; SCHLATTER \& GARCEZ, 2009; BLOCK, 2003). Não se trata aqui, apenas, do manifesto a qualquer professor - quem sabe escrever, falar em latim, o mínimo que seja, é capaz de ler e apreciar melhor os antigos - mas, sobretudo, de trabalhar com a noção de que as línguas estão a serviço da ação humana, uma noção que se vincula a questões de formação de identidade e de inclusão social. Se entendermos que aprender latim significa a crescente participação na comunidade de usuários da língua, se dissolvem não apenas a concepção de aprendizagem baseada em capacidades inatas e a crença de que o significado está no papel, dentro dos livros, mas também a aceitação de um fluxo unidirecional do conhecimento, do professor para o aluno. Enquanto membros de uma comunidade, todos os envolvidos no uso da língua somos colaboradores e coparticipantes. As identidades dos participantes, com os seus interesses e experiências, são o ponto de partida e o ponto de chegada para a interação em sala de aula (SCHLATTER \& GARCEZ, 2009, 2012).

Inversamente, é compreensível que, como consequência da falta de uso da língua, um professor tradicional de latim tenha dificuldades mesmo com o que se propõe exclusivamente, como a declinação de termos simples e correntes, como sermo Latinus, sem mencionar as habilidades para ler - e não decodificar - e escrever em latim. Além disso, restritos a uma perspectiva de língua formalista, o próprio julgamento sobre a linguagem sofre distorções, como veremos em relação às análises de Moreno sobre os neolatinismos. A deficiência do próprio profissional - não apenas no Brasil, mas daqueles que, em todo o mundo, ainda adotam uma abordagem individualista e formalista - é o maior documento das limitações do método.

\section{O latim em "carne e osso"}

Referimos o uso crescente do latim em nossa época, o modelo atual para a aprendizagem de línguas, e agora abordaremos a valoração do Período Clássico Latino e o mito de sua homogeneidade, mostrando que

Organon, Porto Alegre, v. 29, n. 56, p. 99-121, jan/jun. 2014. 
um entendimento equivocado da própria língua latina e de sua história exclui e vilipendia a maior parte do seu patrimônio.

Qualquer sociolinguista colocaria pelo menos em dúvida a afirmação de Moreno de que o latim utilizado após o séc. II d.C., marco final da época conhecida posteriormente como Período Clássico, em que viveram desde Cícero, Júlio César, Horácio, Ovídio (séc. I a.C.) até Sêneca e Plínio (séc. I e II d.C.) era menos latim, por não ser "em carne e osso". O latim "em carne e osso", segundo Moreno, é "sustentado por regras rígidas"; o leitor pensa que autores, clássicos e pós-clássicos, seguiam regras gramaticais, e não o uso do idioma. Além disso, há nesta afirmação um anacronismo inequívoco, já que as "regras rígidas", como as conhecemos hoje, são a herança de uma tradição gramatical que nos chega a partir do séc. XVI. Apesar da existência de célebres gramáticos na Antiguidade, como Varrão (séc. I a.C.), Donato (séc. IV d.C.) e Prisciano (séc. VI d.C.), o exercício nas "escolas" era voltado à prática de expressão e oratória, a partir da consciência visceral que tinham os antigos do poder político e social no uso da palavra (i.a. BENNER \& TENGSTRÖM, 1977; OLSCHKI, 1922).

Mas a maior crítica, além da sociolinguística, que se pode fazer à afirmação de Moreno e à prática diária dos professores de língua latina em geral é a sua decorrente, brutal e sem precedentes, exclusão historiográfica, bibliográfica, humana, porque o patrimônio deixado pelos escritores de todo o mundo (ver Figuras 1 e 2, nos Anexos), que utilizavam a língua romana como língua franca desde o séc. VI d.C, é infinitamente maior do que a literatura produzida no período clássico latino ou em qualquer outro idioma. ${ }^{11}$

Para citar poucos e óbvios ilustres, pergunto-me com que matéria terão sido escritos Confissões (Agostinho, 397/401), A Consolação da Filosofia (Boécio, 524), O Elogio da Loucura (Erasmo de Rotterdam, 1511), Utopia (Thomas More, 1515/1516), e muitas obras fundadoras de disciplinas ou concepções ocidentais, como Sobre as leis da guerra e da paz (Hugo Grócio, 1625), matriz do direito internacional, ou Meditações (René Descartes, 1641), pai do racionalismo. Omito Copérnico, Galileu, Aquino, Lutero, Calvino, Bacon, Kepler, Pascal, Leibniz, Spinoza, Newton, Lineu, cujas obras todas, creio, foram escritas em latim de areia e vento.

Ora, não estou aqui afirmando que Moreno ou a maioria dos filólogos não conheça estas obras ou que não saiba que elas foram escritas em latim. $\mathrm{O}$ que estou dizendo é que por um discurso repetido e preconceituoso tais obras ainda não estão situadas, como deveriam, entre os clássicos da

11 O interessado pode comprovar este fato através de visita à Biblioteca Augustana ou à Biblioteca Latina. Ver, respectivamente, www.fh-augsburg.de/ harsch/augustana.html\#la e www. thelatinlibrary.com. 
literatura latina, respeitando evidentemente a sua localização no tempo e o seu significado histórico. Curiosamente, o que o leitor leigo não sabe e o leitor profissional parece ignorar é que grande número dessas obras, justamente porque foram escritas após o Renascimento dos séc. XIV a XVI, quando se estabeleceu que a excelência de estilo situava-se entre os escritores do Período Clássico e daí terem como guia diamantino esse conjunto de "regras rígidas" (que até então eram, como vimos, preceitos sobre o uso da língua) construído sobretudo a partir dos textos de Cícero, possui um substrato sintático e lexical mais próximo a Cícero do que os seus próprios contemporâneos, como César, como Nepos, o que dizer de Plínio, de Tácito, de Sêneca, todos considerados igualmente clássicos.

Grosso modo, foi a descrição das propriedades sintáticas dos autores recém nominados e a sua difusão em toda a Europa, quando o latim já não era a língua materna de pátria alguma, que permitiu consolidá-lo como língua internacional - status ameaçado pelas mudanças ocorridas na própria língua latina ao final da Idade Média - e estender o seu uso a regiões nunca alcançadas pelo Império. Como hoje pesquisadores escrevem em inglês para serem entendidos pela comunidade acadêmica, mesmo que nunca tenham estado em país de fala inglesa ou sequer escutado essa língua, o uso de uma sintaxe comum e o acréscimo gradativo de vocabulário possibilitaram e possibilitam a inteligibilidade plena de autores distantes séculos um do outro, como hoje acontece, por exemplo, quando lemos Gregório de Matos e Rubem Fonseca. Gozando o prestígio de língua comum em certos domínios linguísticos até avançado séc. XX, entende-se por que os dois maiores matemáticos do séc. XVIII e XIX, Leonard Euler (1707-1783) e Carl Gauss (1777-1855), optassem pelo latim para a divulgação de suas obras, por que até 1848 o latim era a língua oficial da Hungria e da Croácia, e por que até 1920, na Holanda, as dissertações de filologia eram escritas nesta língua. O fascínio pela respublica litterarum, terra da humanidade em que a única fronteira é o latim, traça uma linha ininterrupta de produção entre bilíngues e multilíngues, de Petrarca (1304-1374) a Baudelaire (1821-1867), de Miguel Caro (1843-1909), ex-presidente da Colômbia, ao poeta nova-iorquino Joseph Tusiani (1924), todos usuários da sintaxe clássica, inovando em estilo e criando novos gêneros literários. Conhecer a literatura neolatina é saber que há influência direta de Christiad (Marcus Hieronymus Vida, 1485-1566) na escritura de $O$ Paraíso Perdido, de John Milton (1608-1674), que muitos personagens de $O$ Senhor dos Anéis nasceram a partir das leituras de J. R. R. Tolkien (1892-1973) de Iter Subterraneum (Viagem Subterrânea, Ludvig Holberg,1684-1754) (ver IJSEWIJN, 1990).

Organon, Porto Alegre, v. 29, n. 56, p. 99-121, jan/jun. 2014. 
Mas Moreno afirma que o latim morreu, paralisou-se, cristalizou-se há mil e quinhentos anos. Inúmeros tratados filosóficos, comentários de medicina, de arquitetura, romances, novelas, escritos em todo o mundo desde o Renascimento continuam sem leitura, guardados em bibliotecas, desprestigiados, justamente por se ouvir, de pessoas respeitosas, esse lugarcomum de que não estão escritos em "latim em carne e osso".

Devido ao cataclismo pelo qual o mundo não existiu por mil e quinhentos anos, ou existiu menos, Moreno chega a afirmar que "é possível que nenhum bebê nascido a partir do século 6 da Era Cristã, se tanto, tenha ouvido a voz de sua mãe dizer-lhe palavras doces nesse idioma”. Toda a literatura humanística latina, desde o séc. XIII até o séc. XX, clama uma história diferente. Em famílias privilegiadas e letradas era preceituado que não apenas as mães, mas amas, serviçais, trabalhadores da casa falassem em latim (e grego) exemplares com as crianças ainda in cunabulis, em berço; portanto não o latim, mas falar qual latim era a questão (i.a., ERASMO, 1529; BURKE, 1993, p. 34-65).

O leitor deve entender que tais considerações são fundamentais, porque determinam o que e como ensinar. Graficamente, vejamos a perspectiva avançada do professor Moreno, porque trabalha com a noção de que o latim "em carne e osso" estende-se até o séc. VI, "se tanto", enquanto a maioria das escolas secundárias e departamentos de línguas clássicas em todo o mundo permanece no séc. II d.C. (ver, em negrito, na Figura 1, nos Anexos).

Uma visão de língua baseada no seu uso entre as pessoas e em comunidade entende como legítimas a produção latina e as práticas dos usuários da língua em todas as suas variantes e épocas (ver a Figura 2, nos Anexos. Nas colunas uma amostra meramente representativa de autores que escreveram e escrevem em latim em cada século; a partir do séc. XVI a quantidade de autores que produzem em latim é descomunal).

Se percebemos que a maior parte do patrimônio latino se encontra após a queda de Roma (476 d.C.), e portanto não se detém no século II d.C., mas abarca igualmente a Idade Média, a Idade Moderna e a nossa época, os estudos de língua latina, hoje ameaçados, acrescem significativamente em importância, não apenas para os estudiosos do idioma, mas para todas as disciplinas de humanidades (direito, história, literaturas, etc.). Além disso, a literatura produzida no período dito Clássico adquire novo peso, historicizada e fortalecida, por oferecer uma espécie de ingresso aos períodos posteriores. Esse ingresso, o fundamento sintático e a inspiração primeira, não representa unicamente o caminho para a posteridade, senão permite um trânsito, em que a posteridade retorna a ela, atribui-lhe valor simbólico, esmiuça-a, se afasta (i.a. TUNBERG \& MINKOVA, 2002; TUNBERG, 2002, p. 219-225). 


\section{Os neolatinismos}

Por fim, é preciso dizer algo sobre os neolatinismos. Como nas demais comunidades, tampouco entre os usuários do latim há uniformidade quanto à seleção e ao uso lexical. Ao longo dos séculos editou-se um sem número de dicionários, léxicos, manuais genéricos e específicos a determinadas disciplinas; apenas os jesuítas, por exemplo, entre os séculos XVI e XVIII publicaram inúmeros deles, condensados no final das incontáveis apostilas de catequese. Como exemplo de dicionários de épocas diferentes podemos citar Orbis Sensualium Pictus, de Jan Amos Comenius (1658) e Imaginum Vocabularium Latinum, de Sigrides Albert, Saarbrücken (1998). Moreno apresenta-nos dois dicionários, ambos circunscritos ao Vaticano - um escrito por Antonio Bacci e outro intitulado Lexikon Recentis Latinitatis, ${ }^{12}$ - porque "só o Vaticano não abandonou o uso do latim"; qualquer usuário atual dessa língua sabe que os secretários papais que escrevem em latim lutam para a restauração do uso abolido.

No entanto, como bem ensina o professor Moreno, a língua não faz caso de criações individuais, e não se deve analisar uma língua olhando o léxico, "como se falássemos por meio de definições de dicionário". Porém é exatamente isso que Moreno acaba por fazer: não vendo como legítimas as criações espontâneas e naturais com as quais, ao longo dos séculos, comunidades inteiras ou grupos de pessoas reais comunicavam-se, batizavam objetos também reais, usados para fazerem coisas reais, Moreno simplesmente as ignora e, a fim de expressar a sua opinião sobre o uso atual da língua latina, examina "definições de dicionário".

Se, por outro lado, entendermos como legítimo o uso do latim durante dois mil e quinhentos anos, percebemos que diminui significativamente a necessidade de criar novos vocábulos para os objetos modernos, já que tais palavras surgiram, ao longo dos séculos, natural e gradativamente, "como as árvores da floresta". Justamente porque a comunidade científica adotava o latim como língua franca, as invenções científicas ou a catalogação de novas espécies de fauna e flora obtinham primeiramente o seu nome em latim. Quanto à permanência de denominações para fatos e objetos exclusivos da nossa época, o tempo e o uso dirão. Os usuários de latim não adotam nem as propostas de Bacci, nem as do Lexikon Recentis Latinitatis, entre outras causas, porque são longas, desajeitadas e não incorporam as

12 Bacci, Antonio. Lexikon eorum vocabulorum quae difficilius Latine redduntur. Roma, 1955; Lexikon Recentis Latinitatis, Latinitas Foundation, Vaticano, 1992. Acesso direto ao Lexikon: http://www.vatican.va/roman_curia/institutions_connected/latinitas/documents/rc_ latinitas_20040601_lexicon_it.html

Organon, Porto Alegre, v. 29, n. 56, p. 99-121, jan/jun. 2014 
palavras aceitas em todo o globo, como ensina Moreno. Mas discordamos tanto das análises específicas feitas por ele, quanto das suas formulações. Vejamos, por exemplo, as propostas para biquíni e jazz.

Não utilizamos vesticula balnearia bikiniana para "biquíni", porque há vocábulos assentes e frequentes desde a Antiguidade, atestados também em autores clássicos, para designá-lo: para a roupa de baixo íntima ou parte inferior do biquíni, subligar (Marcial, 3, 84, 4; Plínio, N. H. 12, 59), e para designar sutiã ou a parte superior do biquíni, strophium (ou mamillaria) (Cícero, Har. Resp. 21, 44; Catulo, 64, 65, etc.; para testemunhos pictográficos, veja mosaicos datados do séc. V d.C. em Catullo, 1999, pp. 60-63). O exemplo demonstra que na maioria das vezes sequer é preciso recorrer a vocábulos novos para denominar objetos e atividades cotidianas. Moreno, por outro lado, diz ser termo inadequado porque distante "da brevidade e da concisão que sempre caracterizaram a língua romana", repetindo e reforçando a falsa ideia da homogeneidade da literatura do Período Clássico. Testemunhos que o refutam são inúmeros; unum sufficit. O maior orador da Antiguidade Clássica, reconhecido em todas as épocas como exemplo inequívoco da excelência do estilo romano, Marco Túlio Cícero, foi obrigado a se defender, no outono da vida, da reprovação de jovens literatos, que censuravam o seu estilo ornado, excessivo, ou, na denominação antiga, "asiático", oposto ao estilo que se pressupunha breve e simples, o "ático". O que responde Cícero?

Alguém diz: quero imitar aos áticos. Quais? Já que não há um estilo único. Pois há algo tão díspar como Demóstenes e Lísias? E igualmente como Hipérides? E de todos eles como Ésquilo? Então imitar a quem? Se a alguém, então os outros não escreviam em estilo ático? Se todos, como é possível, se eram entre si o máximo em dissemelhança? (CÍCERO, Brutus, 81, 285).

Cícero, mostrando portanto que erravam os que ensinavam o mito da homogeneidade do Período Clássico Helênico, conta, em Brutus, uma história em que se posiciona como o ápice da tradição literária romana, $a$ despeito do seu estilo ornado e exuberante. ${ }^{13}$ Isso está em Brutus, em toda a obra retórica de Cícero, em Tácito (Dialogus de oratoribus), em Erasmo de Rotterdam (Ciceronianus, Basiléia, 1528), etc.

Para designar a palavra "jazz", Bacci propõe absurda symphonia, com a qual, segundo Moreno, exprime "as crenças e preconceitos de seu criador". Atualmente ou os usuários utilizam a mesma palavra, "jazz", ou, quando não

13 Sobre a variação do estilo de Cícero ver ALBRECHT, 2003. 
conhecemos o nosso interlocutor e queremos demonstrar que sabemos que tal palavra não está atestada entre autores latinos antigos, usamos, na primeira vez de uso, uma circunlocução, como "hoc musicae genus, cui nomen jazz". Mas vejamos a proposta "preconceituosa" de Bacci: o primeiro significado de "absurdus", no Oxford Latin Dictionary (OLD), ou seja, o significado original da palavra ao qual um filólogo deve atentar, é o seguinte (traduzo): “(referente a som): fora de tom, discordante". O exemplo inequívoco é de Cícero: “mollis vox ac muliebris aut quasi extra modum absona atque absurda" (De Oratore, 3, 41), "voz mole e feminina ou como se [fosse] extremamente áspera e discordante". No verbete "symphonia", no OLD, lê-se: "(referente a som): harmonia de sons, concordância”. E assim temos a proposta de Bacci: absurda symphonia, ou seja, "harmonia discordante". No primeiro verbete da Enciclopédia Britânica para “jazz” lê-se (traduzo): “...e caracteriza-se por distorções deliberadas de ritmo e harmonia”. Moreno não traduz absurda symphonia porque presume a transparência dos termos e o preconceito do cardeal Bacci. Creio contudo ter demonstrado não apenas de onde efetivamente provém o preconceito, mas que o crítico, com a crítica, demonstra descuidar até mesmo da variação que ele julga a única legítima: a clássica.

\section{Considerações finais}

Porto Alegre, entre 1999 e 2001, já contou com centenas de usuários de latim, a partir de cursos ministrados no Instituto Goethe da língua romana como língua de uso (APPEL, 2001). Como consequência de um método colaborativo e participativo, e que percebe como legítimos todos os usos do latim, os alunos que estiveram ali não associam a língua latina exclusivamente com a língua de Cícero nem com a língua do Vaticano. E alguns deles ainda são capazes de dizer, com espontaneidade, cissio et birota collisis, ii qui in benzoinae statione opus faciebant arceram arcesserunt, a frase que Moreno infere, no segundo artigo, problemática para verter hoje para o latim ("o táxi e a moto se chocaram, e o pessoal do posto de gasolina chamou uma ambulância”). Quem fala com espontaneidade é capaz de ler, em sua acepção plena, como usuário da língua, como autor, e não decifrar, palavra a palavra, escritores antigos, medievais, modernos e contemporâneos. Curiosamente, o instrumento símbolo da nossa época, a internet, é um dos maiores impulsores do uso crescente do latim, pois permite que latinistas do mundo inteiro, a despeito de sua posição no planeta, conversem em latim e exercitem a língua antiga a diário.

Neste artigo, partindo de textos escritos por Cláudio Moreno no jornal

Organon, Porto Alegre, v. 29, n. 56, p. 99-121, jan/jun. 2014. 
Zero Hora, discutimos a opinião que os profissionais de Letras têm do que é a língua latina e (de como deve ser) o seu ensino. Enquanto currículos nacionais elaborados em vários países por comissões especializadas em ensino de línguas sugerem, baseando-se no entendimento contemporâneo de como aprendemos línguas, um ensino de latim e grego pautado por comunicação, contexto e comunidades, o profissional segue alheio a discussões pedagógicas ou aos estudos sobre o uso da linguagem.

Baseando-se em uma noção de que o que faz uma língua é uma competência inata, fisiológica, se percebe o latim como idioma extinto em 476 A.D. Por isso, o objetivo dos estudos latinos é ler alguns autores que escreveram no século I a.C. ou próximo a esse período, denominado Clássico. Porque se pressupõe a existência de capacidades linguísticas inatas, que não possuímos, toda a interação entre os participantes da aprendizagem e a interação com o texto latino é feita em português. A essa ênfase mentalista se soma a crença correlata de que uma língua se aprende através do estudo de suas regras e da tradução de vocábulos ou frases. Mas embora objetive exclusivamente ler e ler exclusivamente autores clássicos, o profissional de latim (quem dirá o aluno) tem dificuldades mesmo para declinar (quem dirá usar em interação) termos frequentes como sermo Latinus.

Como vimos através da discussão dos textos escritos por Cláudio Moreno, a visão de língua e linguagem divorciada de práticas sociais permite não apenas a manutenção de um estudo abstrato, gramatical, sem atenção ao emprego adequado e eficiente da língua em contextos específicos, mas também distorce o julgamento sobre o idioma, além de desprestigiar e desconsiderar uma história humana e bibliográfica amplíssima e riquíssima.

Não foi o nosso propósito aqui dissertar sobre as particularidades da implementação de uma metodologia de ensino para línguas clássicas como sugerem os currículos nacionais. Quisemos notar que o estudo restrito a um período extremamente limitado de uso do latim, e o modelo de aprendizagem individualista e formalista - de resultados questionáveis mesmo para a formação do profissional - não são uma necessidade nos estudos de filologia clássica, mas decorrentes de uma concepção cognitivista (mentalista) do que significa uma língua e aprender essa língua. ${ }^{14}$

14 Um dos avaliadores anônimos deste artigo sugere que a herança da tradição gramatical talvez explique melhor o ensino atual do latim. Cremos que a tradição gramatical é fruto desta concepção cognitivista de aprendizagem, e a atualiza diariamente em sala de aula. Superar a tradição gramatical - o que chamo aqui abordagem individualista e formalista - requer perscrutar as concepções que fundamentam o nosso exercício diário dentro e fora da sala de aula. No momento em que compreendermos que aprender uma língua e usar interacionalmente uma língua é um e o mesmo fenômeno, é jogar o jogo da linguagem, não há tradição que detenha uma mudança radical de ensino. 
No avesso da teoria e da prática vigentes, se entendermos que uma língua se faz a partir do seu uso entre as pessoas e em comunidade, o patrimônio latino, restrito a poucos autores em poucos séculos, subitamente implode todas as suas fronteiras, temporais e territoriais, e abraça a multifária e pulsante produção de uma comunidade de uso que se estende por mais de vinte séculos. Entender o estudo do latim como participação crescente nas práticas desta comunidade eminentemente letrada implica em fomentar um ensino baseado em práticas sociais, em práticas da comunidade de uso. Saber latim não é seguir uma ordem gramatical, arbitrária e segmentada - primeira declinação, segunda declinação, primeira conjugação, segunda conjugação - mas organizada, desenvolvendo as habilidades de fala, escrita, leitura e audição desde o início da aprendizagem e integradas entre si, para um engajamento crescente em atividades relevantes de letramento (SCHLATTER, 2009; SCHLATTER \& GARCEZ, 2009). Saber latim e grego significa integrar-se nas práticas de comunidades de uso: cumprimentar e apresentar-se, ler e responder a cartas, expressar e refutar ideias, escrever e discutir um livro. Neste sentido, as leituras selecionadas serão representativas da comunidade de uso, bem como adequadas à proposta pedagógica. ${ }^{15}$

Pedimos que o leitor considere a Figura 2, nos anexos. É preciso reivindicar aos estudos de latim não apenas a obra de Plauto, Terêncio, Cícero, Júlio César, Tito Lívio, Virgílio, Horácio, Ovídio, Catulo, Quintiliano, Tácito, Plínio, Sêneca, mas toda e qualquer produção posterior, de Boécio a Pedro Abelardo, de Copérnico a Newton. A lista segue e não se detém em textos cruciais para o surgimento de disciplinas inteiras ou revoluções sociais e do pensamento, mas abarca também todas as práticas letradas da comunidade. Não há, na história social e literária dos homens, produção mais ampla, mais diversificada, mas influente do que a que gerou a comunidade latina, porque foi a produção acadêmica e leiga, pagã e sacra, ao longo de milênios, da maioria dos povos do Ocidente.

Pensamos que uma redefinição metodológica percebendo como centrais as dimensões interacionais no uso da linguagem, e um reconhecimento como sendo legítimo todo o patrimônio da literatura latina, desde o séc. III a. C até a nossa época, podem fazer com que o estudo de língua latina adquira uma importância, literal e metaforicamente, astronômica.

15 Para uma proposta concreta de metodologia de ensino de latim levando em conta as dimensões sociais e interacionais do uso da linguagem e abarcando os vinte séculos de uso do latim conforme discussão neste artigo, ver método de ensino a ser proximamente publicado: ENGELSING, E. Sermo Latinus Lingua Communis (título provisório), Yale University Press.

Organon, Porto Alegre, v. 29, n. 56, p. 99-121, jan/jun. 2014 


\section{BIBLIOGRAFIA}

ALBERT, Sigrides. Imaginum Vocabularium Latinum. Societas Latina: Saarbrücken, 1998.

ABBOTT, Martha; DAVIS, Sally; GASCOYNE, Richard. National Standards and Curricular Guidelines. In: LaFLEUR, Richard (ed.). Latin for the $21^{\text {st }}$ Century. From Concepts to Classroom. Glenview, IL: Scott Foresman-Addison Wesley, p. 44-58, 1998.

ALBRECHT, Michael von. Cicero's style: a synopsis. Leiden, 2003.

APPEL, Myrna. Latim Vivo agora. Disponível em: http://www.geocities. com/circuluslatinus/lvsitane.html

Arquivo acessado em 3 de outubro de 2013.

BENNER, Margareta e TENGSTRÖM, Emin. On the interpretation of learned Neo-Latin: An explorative study based on some texts from Sweden 1611-1716. Studia Graeca et Latina Gothoburgensia, v. 39, Göteborg, 1977. BLOCK, David. The Social-Turn in Second Language Acquisition.

Georgetown University Press, 2003.

BURKE, Peter. "Heu Domine, Adsunt Turcae": a Sketch of a Social History of Post-Medieval Latin, In: The Art of Conversation. Cornell University Press, p. 34-65, 1993.

BUTTON, Graham et alii. Computers, Minds and Conduct. Polity Press, 1995. CATULLO, Luciano. L'Antica Villa Romana del Casale di Piazza Armerina nel Passato e nel Presente Morgantina. Messina: Avvenire, 2000.

CLARK, Herbert. Using Language. Cambridge: Cambridge University Press, 1996. COMENIUS, Jan Amos. Orbis Sensualium Pictus, 1658.

ENGELSING, Eduardo. The Chinese Room: language proficiency and reading in Classics. Publicação prevista para 2014.

. Sermo Latinus Lingua Communis. Yale University Press, no prelo.

ERASMO de Rotterdam. Declamatio de Pueris ad Virtutem ac Literas liberaliter Instituendis, idque protinus a navitate. Antuérpia, 1529.

FIRTH, Alan. Doing not being a foreign language learner. English as a lingua franca in the workplace and (some) implications for SLA. International Review of Applied Linguistics, n. 47, p. 127-156, 2009.

FIRTH, Alan. The discursive accomplishment of normality: On 'lingua franca' English and conversation analysis. Journal of Pragmatics, n. 26, p. 237-259, 2006. FIRTH, Alan; WAGNER, Johannes. S/FL Learning as a social accomplishment: elaborations on a 'reconceptualized' SLA. The Modern Language Journal, Focus Issue, n. 91, p. 800-819, 2007.

FIRTH, Alan; WAGNER, Johannes. On discourse, communication, and (some) fundamental concepts in SLA research. The Modern Language Journal, n. 81 (3), p. 285-300, 1997. 
GRUBER-MILLER, John. Communication, Context, and Community. Integrating the Standards in the Greek and Latin Classroom. In: GRUBER-MILLER, John (ed.). When Dead Tongues Speak. Teaching beginning Greek and Latin. Oxford University Press, p. 9-23, 2006.

IJSEWIJN, Joseph. Companion to Neo-Latin Studies. tomo I. Louvain, 1990. MARKEE, Numa. Toward an Ethnomethodological Respecification of Second-Language Acquisition Studies. In: TARONE, Elaine M.; GASS, Susan M.; COHEN, Andrew D. (eds.). Research methodology in second language acquisition. Hillsdale, N.J.: Lawrence Erlbaum, p. 89-116, 1994. MORENO, Cláudio. Absurda Sinfonia, Zero Hora, Porto Alegre, 3 de fevereiro, 2007.

Latinório Moderno, Zero Hora, Porto Alegre, 17 de fevereiro, 2007. MORGAN, David. De Seminario Brasiliensi, Melissa, n. 102, p. 1-2, Bruxelas, 2001.

OLSCHKI, L. Geschichte der neusprachlichen wissenschaftichen Literatur. Tomo I e II. Leiden, 1922.

SCHLATTER, Margarete. O ensino de leitura em língua estrangeira na escola: uma proposta de letramento. Calidoscópio, São Leopoldo, v. 7, n. 1, p. 11-23, 2009. SCHLATTER, Margarete; GARCEZ, Pedro; SCARAMUCCI, Matilde: O papel da interação na pesquisa sobre aquisição e uso de língua estrangeira: implicações para o ensino e para a avaliação. Letras de Hoje, 39 (3): p. 345-378, 2004.

SCHLATTER, Margarete; GARCEZ, Pedro M. Línguas adicionais (Espanhol e Inglês). In: RIO GRANDE DO SUL, SECRETARIA DE ESTADO DA EDUCAÇÃO, DEPARTAMENTO PEDAGÓGICO, Referenciais curriculares do Estado do Rio Grande do Sul: linguagens, códigos e suas tecnologias (p. 127-172). Porto Alegre: SE/DP, 2009. SCHLATTER, Margarete; GARCEZ, Pedro M. Línguas adicionais na escola: aprendizagens colaborativas em Inglês. Erechim: Edelbra, 2012. SEARLE, John. Minds, Brains, and Programs. The Behavioral and Brain Sciences. 3 (3), 1980.

TUNBERG, Terence e MINKOVA, Milena. De Kentuckiano Instituto studiis Latinis provehendis, In: Acta Selecta Decimi Conventus ALF, Madrid, p. 283-289, 2002.

TUNBERG, Terence. Cur opera Latina non solum classica, sed recentiora etiam omnibus litterarum classicarum studiosis proponi praelegique debeant. In: Acta Selecta Noni Conventus ALF, Roma, p.219-225, 2002. WITTGENSTEIN, Ludwig. Philosophische Untersuchungen (Philosophical Investigations), ed. G.E.M. Anscombe e R. Rees. Oxford: Basil Blackwell, 1958 [1953, primeira edição].

Recebido em: 11/12/2013. Aceito em: 22/03/2014.

Organon, Porto Alegre, v. 29, n. 56, p. 99-121, jan/jun. 2014. 
ANEXOS

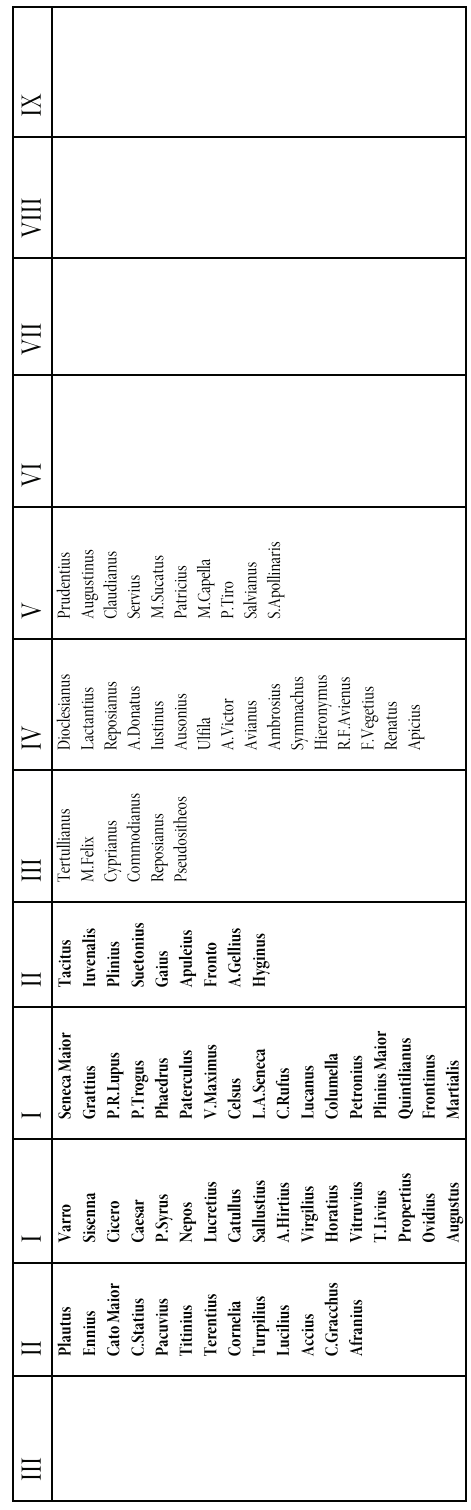

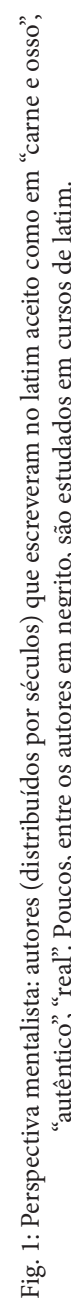

Organon, Porto Alegre, v. 29, n. 56, p. 99-121, jan/jun. 2014. 

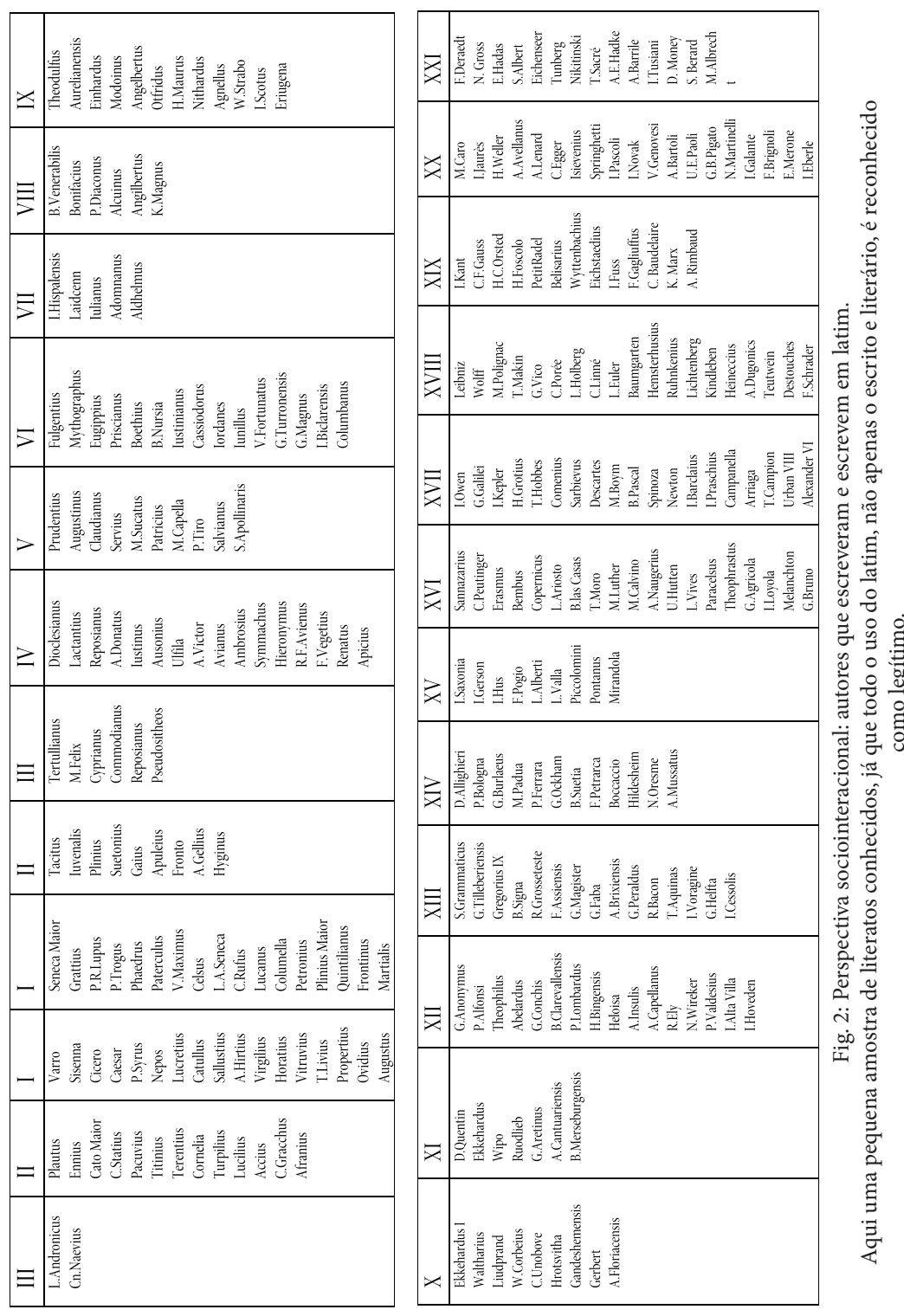

Organon, Porto Alegre, v. 29, n. 56, p. 99-121, jan/jun. 2014. 